\title{
Genetic Structure of Heterobasidion annosum in White Fir Mortality Centers in California
}

\author{
Matteo Garbelotto, Fields W. Cobb, T. D. Bruns, William J. Otrosina, Tina Popenuck, and Garey Slaughter
}

\begin{abstract}
First, second, third, fifth, and sixth authors: Department of Environmental Sciences, Policy, and Management, 151 Hilgard Hall, University of California, Berkeley 94720; and fourth author: USDA Forest Service, Forestry Sciences Laboratory, Tree Root Biology Team, 320 Green Street, Athens, GA 30602.
\end{abstract}

Accepted for publication 15 March 1999.

\begin{abstract}
Garbelotto, M., Cobb, F. W., Bruns, T. D., Otrosina, W. J., Popenuck, T., and Slaughter, G. 1999. Genetic structure of Heterobasidion annosum in white fir mortality centers in California. Phytopathology 89:546-554.

The structure of Heterobasidion annosum populations was studied in 15 mixed-conifer sites in central and northern California. Study sites displayed mortality of white fir trees in enlarging discrete patches (mortality centers). At each site, fungal genotypes were defined by somatic compatibility tests. In two sites, further genetic and molecular analyses were performed on field genotypes and on homokaryons obtained by dedikaryotization of field heterokaryons. Isolates were found to be colonizing mostly the roots and the bole sapwood of white fir trees, and no significant infections of other tree species were observed. Each mortality center was characterized by the presence of several fungal genotypes, all belonging to the S intersterility group. Both homokaryotic and heterokaryotic strains were present in all sites. Multiple genotypes were retrieved in individual trees or stumps. Out of 228 fungal genotypes, $86 \%$ were found only with-

two largest genotypes had diameters of 9 and $10 \mathrm{~m}$, and had colonized five and nine trees, stumps, or both, respectively. The maximum distance between two adjacent trees colonized by the same genotype was $6 \mathrm{~m}$, and a highly significant correlation was found between tree diameter and distance of fungal "vegetative" spread. The largest clones were found in areas characterized by high tree and stump densities, and secondary spread of the fungus was more significant in denser stands. In most cases, original infection courts of existing genotypes could be traced to standing trees and not to stumps. The genetic analysis performed in two mortality centers revealed that most local genotypes had different mating alleles, and thus originated from unrelated basidiospores. In a few cases, the same mating allele was shared by two heterokaryons $(n+n$ genome) or by a homokaryon (n genome) and a heterokaryon. Molecular analysis showed that nuclei bearing the same mating allele were identical, providing evidence that the two nuclei forming heterokaryons can act independently in the field and can be shared among isolates, presumably via di-mon mating or by separate matings of different portions of widespread homokaryons.
\end{abstract} in a single tree or stump, while $14 \%$ had spread to adjacent trees. The
Heterobasidion annosum (Fr.:Fr.) Bref. is a basidiomycete affecting a wide array of coniferous tree species worldwide $(9,26$, $31,45)$. Studies on the etiology of this pathogen in Pinus spp. $(28,41)$ and Picea spp. $(33,34,56)$ have indicated that stumps are important sites for fungal primary infections, presumably via basidiospores. The creation of stumps by extensive logging of conifer forests has favored the establishment of this pathogen in stands where originally it may have been rare (52). Once H. annosum is established in a pine or spruce stand, its pathogenic effects can be detected as patches of mortality that enlarge over time to encompass adjacent susceptible host trees (36); these are known as mortality, infection, or root-disease centers. Root-to-root grafts and contacts allow the mycelial colonization of trees adjacent to the initially infected stumps $(26,40,53)$. Conversely, there is no evidence that the fungus can grow freely in the soil $(15,49,50)$.

Mortality centers in Norway spruce and pine stands or plantations encompass several fungal genotypes $(11,25,53,56)$. Although a single genotype per tree has been described in Norway spruce, some genotypes can colonize several trees (53). In pine plantations, the diversity of mating alleles in spatially confined areas suggests that initial infections occur via unrelated basidiospores (11). In this regard, H. annosum appears to represent an intermediate situation between root pathogens, with a great secondary spread-

Corresponding author: M. Garbelotto; E-mail address: matteo@nature.berkeley.edu

Publication no. P-1999-0423-01R

This article is in the public domain and not copyrightable. It may be freely reprinted with customary crediting of the source. The American Phytopathological Society, 1999. ing ability (e.g., some Armillaria spp. and Phellinus weirii) $(3,42)$, and wound pathogens or decay basidiomycetes $(16,29,38)$, characterized by the presence of numerous less extensive genotypes in a limited space.

Although mortality centers resembling those in pine and spruce stands can also be observed in Abies spp. stands, the population structure of $H$. annosum in such centers has yet to be determined. The pathogen can be found both in the roots and in the boles of true firs, and it has been hypothesized that trees may be infected both by secondarily spreading mycelia from the roots of adjacent trees and by airborne basidiospores landing on wounds $(2,36)$. These hypotheses remain mostly untested. Differences in the etiology and epidemiology of the disease may be determined not only by the different host species and ecosystems involved, but also by the genetic differentiation of populations of the pathogen found on different host species and in distant regions of the world. H. annosum, in fact, comprises at least three intersterility groups (ISGs) that display marked host preferences $(9,61)$. Furthermore, each ISG is subdivided in genetically isolated populations according to their broad geographic provenance $(18,35)$. Different ISGs cause distinct symptoms on each host species, and host-specific dynamics affect infection and spread $(26,36)$. For instance, primary infections by $\mathrm{S}$ isolates on Tsuga spp. in North America occur both on stumps and on wounds in live trees (39).

Knowledge of the population structure of fungi provides important insights on their biology, ecological strategies, and epidemiology. The relative importance in nature of mitotic versus meiotic progeny, occurrence of somatic mutation and recombination events, and incidence of secondary "vegetative" spread and primary infections are some of the aspects that have been elucidated by 
population genetics studies in other forest pathosystems (2). We studied the population structure of $H$. annosum in 15 white fir (Abies concolor (Gordon \& Glend.) Lindl. ex Hildebr.) mortality centers in California in order to describe patterns and modes of disease development (e.g., parts of the trees more often colonized by the pathogen and symptoms associated with the fungal colonization, tree species infected, and ISG of fungal isolates collected). This information is useful in understanding when and where initial infection occurs and in testing the proposed host specificity of the two ISGs of this pathogen present in North America (61). In addition, answers to each of the following questions were sought in order to improve our understanding of relevant correlated biological end epidemiological processes. (i) How many $H$. annosum genotypes are involved in individual white fir mortality centers? (ii) Are stumps important primary infection centers as it occurs in pine and spruce stands? (iii) What is the spatial distribution and size of fungal genets? (iv) What stand characteristics favor secondary tree-totree spread? Two variables were analyzed: stand density and tree size. (v) What is the genetic relatedness of fungal genotypes encountered in a site?

These questions were addressed by determining frequency, size, and distribution of fungal genotypes and by overlapping maps of fungal genets with maps of host distribution in mortality centers. This analysis was done in a dynamic way by reconstructing the history of each study site through written records and surviving evidence of previous logging activities and disease incidence. The identity and relatedness of fungal genotypes, as well as patterns of fungal genetic variability at the local scale, were inferred from somatic compatibility (sc) tests, mating alleles study, and polymerase chain reaction (PCR)-based fingerprinting analysis.

\section{MATERIALS AND METHODS}

Study sites, sampling, and isolations. We studied 15 white fir mortality centers in 12 mixed-conifer stands having a predominance of white fir (Table 1). Five centers were in the southern Cascade mountain range (one stand in the Plumas National Forest and three in the Lassen National Forest), and the remaining 10 were in the northern and central Sierra Nevada mountain range (four stands in the Eldorado National Forest and four in the Stanislaus National Forest). All sites were located in stands that had been logged at least once in the past. Study sites corresponded to visually defined discrete mortality centers in which signs of both old and recent $H$. annosum-related mortality were present. Infection centers were delimited either by a discontinuity in the tree cover (e.g., a road) or by a zone of seemingly healthy trees encircling a patch of symptomatic and dead trees. Areas of study sites ranged from 155 to $1,050 \mathrm{~m}^{2}$ (Table 1).

In each study site, all trees and stumps with diameters over $4 \mathrm{~cm}$ were mapped. General health conditions of live trees were described using indicators such as the live crown ratio, the crown shape index, the color of the foliage, and the reduction in terminal growth (51). Time of death was estimated for dead trees and snags based on the amount and the color of the retained foliage. Time since felling was estimated for stumps based on the state of decay of the stump wood. Presence and location of decay pockets on the stump tops were noted and used as an indication that the tree had been infected and colonized by $H$. annosum prior to being felled. This is based on the fact that when stumps become infected upon tree felling, the fungus penetrates the outer surface of the stump without causing any noticeable decay in the top few centimeters.

Above-ground sampling of all trees and stumps in each plot was performed by felling trees and snags or by cutting off the top portion of stumps to obtain a 7- to 9-cm-thick transversal bole section ("disk") near the root collar. Sample disks were marked so that the exact location of $H$. annosum colonies and decay patches on each tree or stump could be determined. After noting the presence of discoloration and decay, disks were sealed in plastic bags and incubated for 6 to 10 days at room temperature. Basidiocarps, usually found in stump decay pockets, were also collected and stored at $10^{\circ} \mathrm{C}$.

Below-ground sampling was performed by excavating the root systems of most sample trees and stumps and by excising transversal root disks at 1 to $2 \mathrm{~m}$ from the root collar. The number of roots sampled (1 to 11) increased with the increasing diameter of sample trees or stumps. Only roots with a diameter larger than $2 \mathrm{~cm}$ were sampled. Root disks were quickly sealed and were incubated as described above for bole disks.

At the end of the incubation period, isolations were made by transferring infected wood or hyphae of the imperfect state of $H$. annosum (Spiniger meineckellum (A. Olson) Stalpers) from the wood surface onto a petri dish previously filled with wood-rotting basidiomycetes selective (27) or standard (1.25\% malt and $1.5 \%$ agar) malt extract agar (MEA) media. Isolates were also obtained from the context of all collected basidiocarps. All isolates were subsequently duplicated and stored at $10^{\circ} \mathrm{C}$ on MEA.

Nuclear and genotypic characterization of fungal isolates. The following methods were employed to classify isolates from

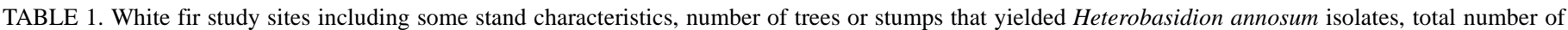
isolates collected, and number of genets determined by somatic compatibility tests

\begin{tabular}{|c|c|c|c|c|c|c|c|c|c|}
\hline $\begin{array}{l}\text { Plot and } \\
\text { national forest }^{\mathrm{a}}\end{array}$ & $\begin{array}{c}\text { Area, } \\
\mathrm{m}^{2}\end{array}$ & $\begin{array}{l}\text { Density, } \\
\text { stems/ha }^{b}\end{array}$ & $\begin{array}{c}\text { Basal } \\
\text { area/ha, m }{ }^{2 b}\end{array}$ & $\begin{array}{l}\text { Average dbh }{ }^{\mathrm{c}}, \\
\mathrm{cm}(\mathrm{SD})\end{array}$ & $\begin{array}{l}\% \text { of basal area } \\
\text { to yield isolates }\end{array}$ & $\begin{array}{l}\text { Stems with } \\
\text { H. annosum }\end{array}$ & $\begin{array}{l}\text { Isolates } \\
\text { collected }\end{array}$ & $\begin{array}{l}\text { No. of } \\
\text { genets }^{\mathrm{d}}\end{array}$ & $\begin{array}{l}\text { Genets found on } \\
\text { two or more trees }\end{array}$ \\
\hline Loggers, St. & 960 & 438 & 120 & $53(26)$ & 31 & 10 & 53 & 30 & 1 \\
\hline Cougar, St. & 192 & 1,042 & 102 & $31(17)$ & 19 & 5 & 25 & 13 & 2 \\
\hline Owl, St. & 196 & 918 & 92 & $33(15)$ & 9 & 5 & 6 & 6 & 0 \\
\hline Woodpile, St. & 193 & 1,554 & 113 & $28(12)$ & 53 & 17 & 62 & 9 & 4 \\
\hline Lumberyard, Eld. & 1,050 & 962 & 119 & $34(20)$ & 25 & 17 & 49 & 29 & 3 \\
\hline Dark Cyn., Eld. & 900 & 456 & 105 & $49(23)$ & 26 & 7 & 26 & 14 & 1 \\
\hline Meis Cabin, Eld. & 300 & 1,100 & 150 & $36(22)$ & 47 & 9 & 69 & 22 & 1 \\
\hline Huey, Eld. & 512 & 1,133 & 140 & $34(20)$ & 48 & 22 & 67 & 29 & 8 \\
\hline Duey, Eld. & 400 & 1,175 & 140 & $33(20)$ & 14 & 6 & 13 & 5 & 1 \\
\hline Luey, Eld. & 750 & 920 & 79 & 28 (19) & 22 & 11 & 32 & 15 & 2 \\
\hline Mountain View, Pl. & 864 & 1,111 & 76 & $27(11)$ & 18 & 13 & 41 & 11 & 3 \\
\hline Ridge 1, Las. & 304 & 658 & 74 & $36(13)$ & 54 & 12 & 45 & 19 & 3 \\
\hline Ridge 2, Las. & 155 & 1,290 & 110 & $31(11)$ & 40 & 7 & 31 & 12 & 2 \\
\hline Obsidian 1, Las. & 195 & 615 & 164 & $52(27)$ & 37 & 2 & 7 & 6 & 0 \\
\hline Obsidian 2, Las. & 192 & 469 & 279 & $82(30)$ & 22 & 3 & 26 & 8 & 1 \\
\hline Total & 7,163 & $\ldots$ & $\ldots$ & $\ldots$ & $\ldots$ & 146 & 552 & 228 & 32 \\
\hline
\end{tabular}

${ }^{\text {a }}$ St. = Stanislaus National Forest, Eld. = Eldorado National Forest, Pl. = Plumas National Forest, and Las. = Lassen National Forest.

b Includes live and dead trees, stumps, and snags.

${ }^{\mathrm{c}} \mathrm{dbh}=$ Diameter at breast height.

${ }^{\mathrm{d}}$ Determined by somatic incompatibility tests. 
seven white fir mortality centers as either homokaryons or heterokaryons (19): (i) type of somatic interaction with testers of known ploidy (homokaryon-heterokaryon interactions are different from homokaryon-homokaryon interactions) (54); (ii) migration of arbitrary-primed (AP)-PCR molecular markers (heterokaryons will have markers diagnostic of each parental homokaryon) (14); (iii) presence/absence of clamp connections at hyphal septa (homokaryons are clampless) (31); and (iv) mating tests (clampless homokaryons become clamped heterokaryons upon mating with compatible testers) (12,31). To be classified as a homokaryon, an isolate had to satisfy requirement iii and at least one of the other requirements.

The ISG of the isolates was determined by taxon-specific competitive-priming (TSCP) PCR (20).

Somatic incompatibility groups (SIGs) were defined by sc tests (53). Besides standard heterokaryon-heterokaryon pairings, homokaryon-homokaryon and homokaryon-heterokaryon tests were included and scored in a way comparable to the scoring of heterokaryon-heterokaryon pairings (presence or absence of a reaction zone). Initially, sc tests were performed on all isolate combinations from individual trees. Subsequently, a single "tester" isolate was randomly chosen to represent each within-tree genotype. Finally, tester isolates were paired in all possible combinations. Two sets of each sc pairing were performed. In a second stage, $20 \%$ of the sc tests were randomly chosen to be repeated.

In the centers Ridge 2 (Lassen National Forest) and Cougar (Stanislaus National Forest), fungal isolates were analyzed by the AP-PCR technique (58). The genotype of each isolate was determined by scoring the presence or absence of PCR-amplified bands. The PCR primers used individually or in pairs are shown in Table 2. When pairs of primers were used, combinations were such that no defined fragment was expected. Conditions described by Stenlid et al. (55) were used for the primers M13 and $\mathrm{GTG}_{5}$, conditions for all other primers were as described by Garbelotto et al. (19). PCR products were electrophoresed on a $1.5 \%$ agarose gel at $100 \mathrm{mV}$ for $1 \mathrm{~h}$ in $0.5 \times$ Tris-acetate buffer $(100 \mathrm{mM}$ Tris, $12.5 \mathrm{mM}$ sodium acetate, and $1 \mathrm{mM}$ EDTA, $\mathrm{pH} 8.1$ ), stained with ethidium bromide, and photographed under UV light.

The ML5-ML6 region of the large rRNA (LrRNA) gene of the mitochondria was amplified for all isolates from Cougar and Ridge 2, as described by Garbelotto et al. (20).

Dedikaryotization of heterokaryons, mating allele determination, and fingerprinting of derived haploid isolates. Heterokaryons in the two centers Ridge 2 and Cougar were dedikaryotized as follows. Each heterokaryon was grown on cellophane sheets overlaid on water agar medium in a 9-cm-diameter petri dish. At least five replicates were made for each isolate. After 7 to 10 days,

TABLE 2. Sequences of DNA oligonucleotide primers used for the arbitraryprimed polymerase chain reaction analysis

\begin{tabular}{lll}
\hline Primer & \multicolumn{1}{c}{ Sequence $\left(5^{\prime}\right.$ - $^{\prime}$ ) } & \multicolumn{1}{c}{ Reference } \\
\hline NS1.5R & TCTAGAGCTAATACATGC(T/C)G & \multicolumn{1}{c}{ White et al. (59) } \\
NS2 & GGCTGCTGGCACCAGACTTGC & White et al. (59) \\
NS3 & GCAAGTCTGGTGCCAGCAGCC & White et al. (59) \\
NS5 & AACTTAAAGGAATGACGGAAG & White et al. (59) \\
NS6 & GCATCACAGACCTGTTATTGCCTC & White et al. (59) \\
ITS2 & GCTGCGTTCTTCATCGATGC & White et al. (59) \\
ITS4b & CAGGAGACTTGTACACGGTCCAG & Gardes and Bruns (22) \\
M13 & GAGGGTGGCGGTTC & Stenlid et al. (55) \\
ML5 & CTCGGCAAATTATCCTCATAAG & White et al. (59) \\
ML6 & CAGTAGAAGCTGCATAGGTC & White et al. (59) \\
MLin3 & CGACACAGGTTCGTAGGTAG & Y. Li (32) \\
KimQ & ACGCCTCTAAGTCAGAAT & Kim et al. (30) \\
KJ2 & GCTTGAAATTGTCGGGAGGG & T. Bruns, unpublished \\
CNS3.6 & AATGAAGTCATCCTTGGCAG & T. Bruns, unpublished \\
NL13 & CAACGCAACTTCATGCACG & T. Szaro, unpublished \\
CNL2F & GTTTCCCTTTTAACAATTTCAC & White et al. (59) \\
Ctb6 & GCATATCAATAAGCGGAGG & T. Bruns, unpublished \\
Mb2 & GTGAGTTTCCCCGTGTTGAG & M. Berbee, unpublished \\
\hline
\end{tabular}

at least eight hyphal tips were isolated from each plate and grown on MEA. The 40 single-hyphal tip cultures thus obtained from each isolate were observed under a light microscope $(\times 300)(11)$, and the presence or absence of clamps was noted. Clamped cultures were discarded, and clampless cultures were retained as putative homokaryons. One of the putative homokaryons was randomly selected and paired with nine other putative homokaryons obtained from the same heterokaryons. All 10 putative homokaryons were also paired with a standard tester homokaryon in order to verify their ability to mate and form clamps. Matings were performed by transferring plugs of MEA colonized by the fungus on sterile MEA plates. Each mating was repeated at least twice. Plugs from two putative homokaryotic cultures were placed $1 \mathrm{~cm}$ apart in the center of a 9-cm-diameter petri dish. The plate was then incubated for 7 to 14 days and analyzed for the presence of clamps under the light microscope. Clampless plates were analyzed again at approximately 21 days. If at 21 days the matings were still clampless, a plug of MEA was transferred from the mating plate to a new MEA plate, subculture for 2 to 3 weeks, and analyzed once again for the presence of clamps. When two putative homokaryons successfully mated (i.e., they formed a thallus bearing clamp connections), they were considered to bear different mating alleles and to be the two parental homokaryons of the heterokaryotic isolate from which they had been obtained.

Complete mating allele surveys for the Ridge 2 and Cougar infection centers were performed by pairing parental homokaryons from each center in all possible combinations. All homokaryons were also mated with a standard homokaryotic tester to verify their ability to mate and form clamps. Isolates that were retrieved from the field as homokaryons were included. Based on the results of the experiment and on the bipolar nature of the mating system of $H$. annosum (12,31), arbitrarily named mating alleles were assigned to each isolate.

When the same mating allele occurred in two or more homokaryotic isolates, AP-PCR fingerprints were obtained to determine whether isolates bearing the same mating allele also had the same DNA fingerprint.
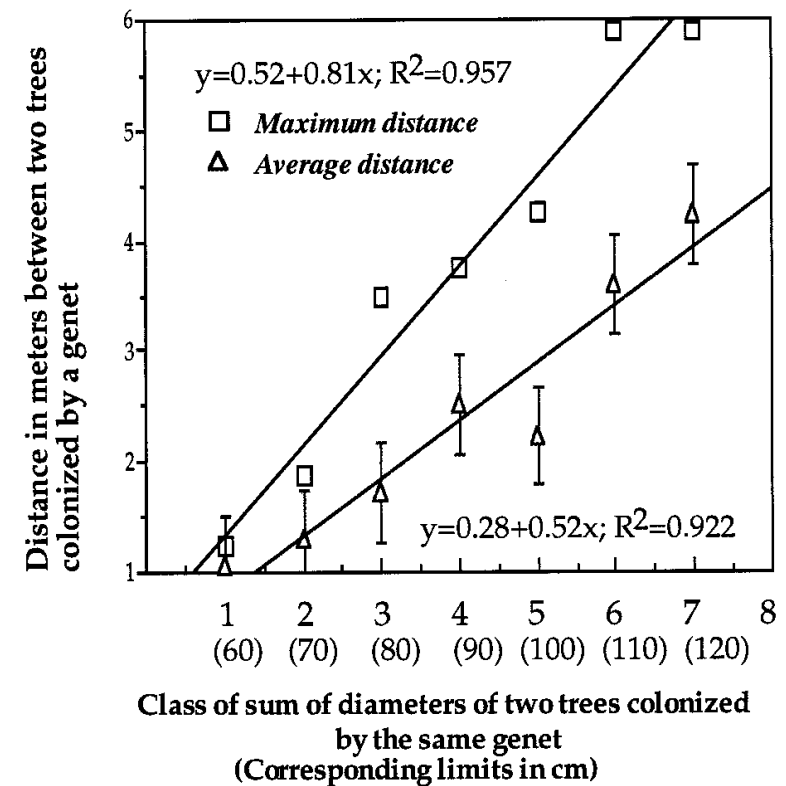

Fig. 1. Linear regression of the sum of the diameters of pairs of stems (trees or stumps) colonized by individual Heterobasidion annosum genets and the distance between the two stems in each pair. Position of the two stems in each pair suggested that the fungus had spread directly from one to the other through contact points or grafts in the two root systems. Stem pairs were divided into classes according to the sum of their diameters at root collar (for stumps) or at breast height (for trees), and for each class, the maximum and average between-stems distances were calculated. 
Frequency and distribution of fungal genotypes; relationships between tree diameter or stand density and the secondary spread of $\boldsymbol{H}$. annosum. Isolates in the same SIG (and with the same AP-PCR fingerprint in the Ridge 2 and Cougar centers) were considered to be part of the same genotype. Minimum putative boundaries of the area occupied by each genotype were determined by enclosing points in which the same genotype was retrieved with a continuous line. Fungal individuals belonging to the same genotype were assumed to represent a unit of $H$. annosum populations and were defined as representatives of the same genet (38). We use the broader definition of genet by Anderson and Kohn (2) to include both homokaryotic and heterokaryotic genotypes. The area occupied by each genet was superimposed on the general map of each study site. This allowed for the determination of (i) the number of trees and stumps colonized by each genet, and (ii) the number of genets present in each tree or stump. The basal area colonized by each genet was calculated by using the sum of the basal areas of trees colonized by a genet. When more than one genotype was found in a tree, only a portion of the basal area proportional to the abundance of that genotype on that tree was assigned to each genotype.
Estimates of rates of fungal spread for individual genets were determined by choosing the most likely location of initial infection courts (i.e., the tree colonized by the genet that had been dead the longest) and by estimating the timing of the progressive onset of new symptoms (i.e., time incurred since tree death and degree of wood decay displayed by trees or stumps colonized by a genet) in an area surrounding the initial infection court.

Distances between all pairs of adjacent trees or stumps (both are referred to as stems) colonized by the same genet were calculated. Only pairs for which direct contagion between the two stems was unequivocal were taken into account. Regression analyses were employed to study the relationship between the distance covered by a genet between each stem pair and the size of the stems involved. Pairs of trees were assigned to stem diameter classes (Fig. 1). For each class, the average distance between stem pairs and the maximum distance between stem pairs were determined. Average and maximum distances were then regressed against the diameter of the largest stem in the pair, the diameter of the smallest stem in the pair, and the sum of the diameters of both stems.

The relationship between stem density or basal area and secondary spread of $H$. annosum was determined by comparing the stem

TABLE 3. Somatic compatibility (SC) groups, ploidy, mating alleles, and arbitrary-primed-polymerase chain reaction fingerprints for 36 isolates of Heterobasidion annosum

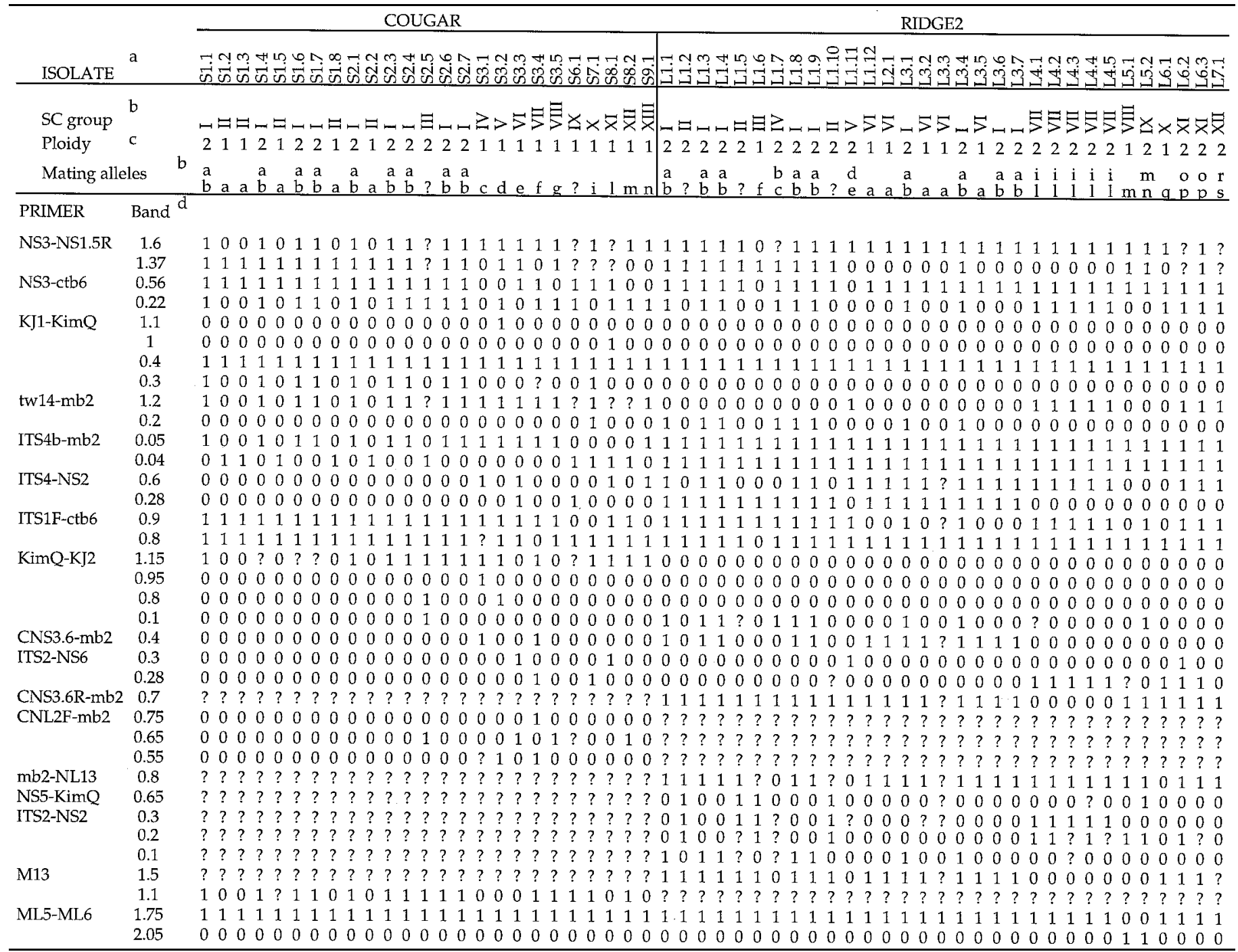

${ }^{a} \mathrm{~S}=$ Cougar site in the Stanislaus National Forest; and $\mathrm{L}=$ Ridge 2 site in the Lassen National Forest. The first number = sample tree or stump; and the second number $=$ isolate.

${ }^{\mathrm{b}}$ Designation for SC groups and mating alleles in Cougar and Ridge 2 is identical, but comparison between the two sites have not been performed.

c 1 = Homokaryotic isolate; and 2 = heterokaryotic isolate.

d Size of amplicons (in kilobases) approximately determined by comparison with molecular standards. $0 / 1=$ amplicon (band) present/absent; and ? = not reliably amplified or amplification not performed. 
densities of sites in which at least two genets had secondarily spread to two or more stems with the stem densities of sites in which zero or one genets had spread secondarily, using Student's $t$ test.

\section{RESULTS}

Isolate collection. A total of 552 isolates was collected from 37 stumps, 42 dead trees, and 67 live trees in the 15 study sites. The number of isolates obtained in each plot ranged from 6 to 69 (Table 1). Except for one live ponderosa pine and one live incense cedar, all samples came from white fir trees. Of the live fir trees positive for H. annosum, $54 \%$ were symptomatic, $33 \%$ were asymptomatic, and $13 \%$ were of undetermined health. Symptoms included thin crown, reduced height growth, off-color foliage, low live crown ratio (calculated as portion of the tree height occupied by the live crown), presence of pathological wetwood, and sapwood or heartwood decay. Asymptomatic trees displayed extensive $H$. annosum colonies in slightly discolored portions of the bole sapwood. Seventy percent of the "positive" stumps displayed typical decay pockets on the tops, an indication that the tree had been infected by $H$. annosum before being felled. The remaining stumps had intact top surfaces, suggesting that either they had been infected after the tree was felled or that, at the time of cutting, the fungal colonization was only in the roots or in the lower part of the bole. The combination of bole and root sampling proved efficient, because in many instances isolates were not collected from both the bole and roots of the same tree. A total of 233 isolates was obtained from roots and 319 from boles. Of all the bole isolates, $97 \%$ came from the sapwood and 3\% were found in the heartwood.

ISG determination, ploidy, and genet identification. TSCP PCR indicated all isolates belonged to the S ISG. sc tests identified 228 different genets in 15 sites (Table 1); 6\% of pairings were undetermined. Up to eight different genets were retrieved in individual trees or stumps. Averages of 1.86 (standard deviation $[\mathrm{SD}]=$ 1.88 , range 1 to 8 ) and 2.1 ( $\mathrm{SD}=1.53$, range 1 to 6 ) genets were found per tree and stump, respectively. Genotypes in the heartwood were also found in the sapwood. Both homokaryotic and heterokaryotic genets were found (19) in the study sites. In Cougar and Ridge 2, 64 and $23 \%$ of the isolates were homokaryotic, respectively. Although sc tests are based on interactions between het-

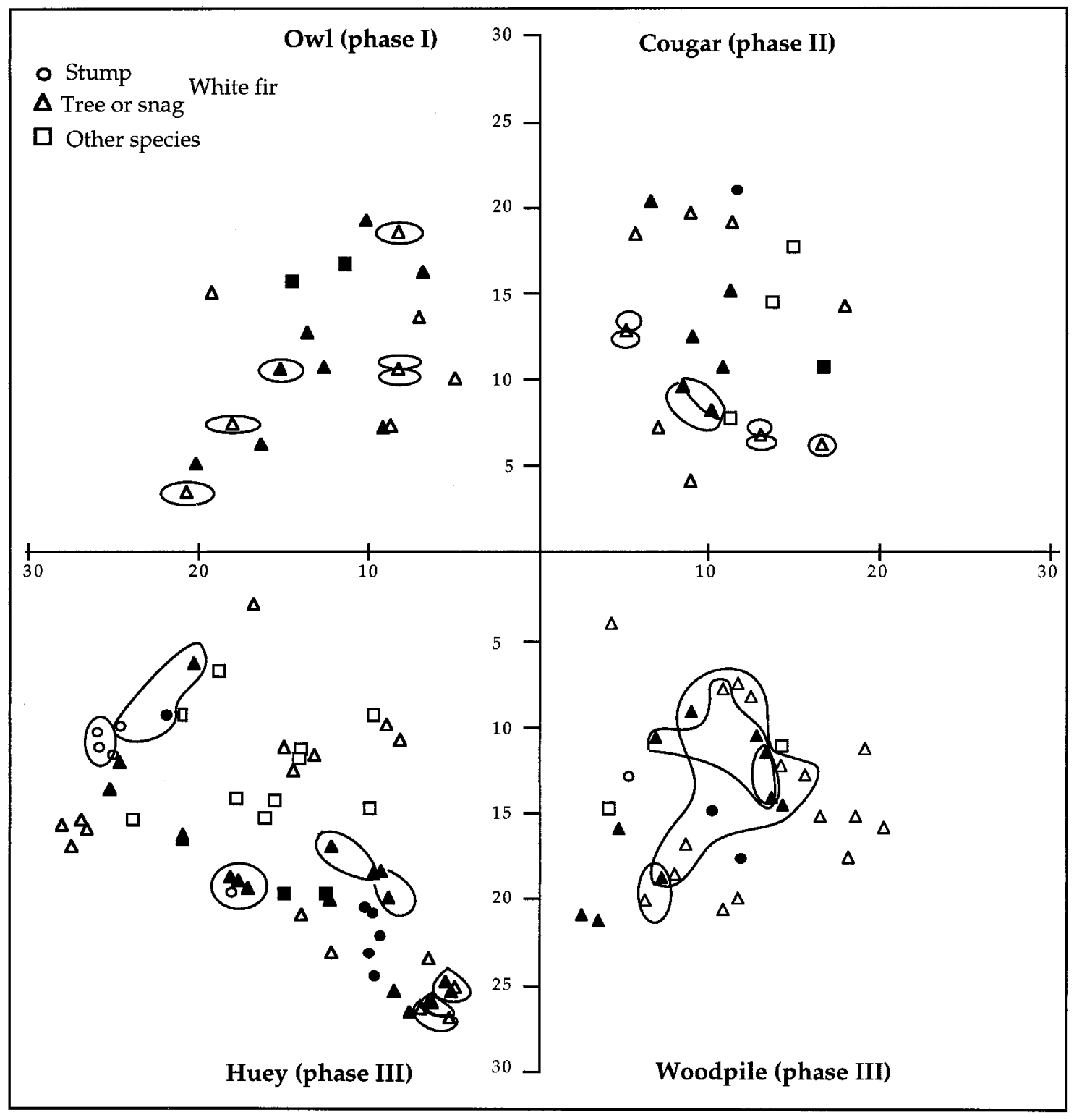

Fig. 2. Continuous solid lines visualize four progressive patterns of distribution of larger Heterobasidion annosum genets in white fir at four study sites. Distances are in meters. Shaded triangles indicate dead trees or snags; shaded circles indicate stumps with evident decay pockets; and other species include Douglas fir, black oak, sugar pine, and ponderosa pines. Progressive advancement of the disease is suggested between phases I and III; older age of fungal clones and a stand structure favorable to secondary spread may be responsible for the more preeminent presence of multitree genets (described in text). 
erokaryons (37), we were able to differentiate homokaryons by scoring the type of interaction on a petri dish in a fashion equivalent to that of sc tests. Homokaryon-homokaryon pairings were scored as negative, and the two genotypes were regarded as different if an obvious interaction zone was noted between the two isolates. The interaction observed was actually the result of a positive mating reaction and could be checked by verifying the presence of newly formed clamps.

AP-PCR fingerprints (Table 3) could be used to differentiate isolates. Thirteen genotypes were identified in Cougar and 12 in Ridge 2. Results obtained by sc tests and AP-PCR fingerprinting were identical in these two plots, regardless of the ploidy of the isolates.

Patterns of genet establishment and spread. At all sites, many fungal genotypes (genets) were retrieved (Figs. 2 and 3). The number of genets per plot averaged $15(\mathrm{SD}=8.8)$ and ranged from 6 to 30. At each site, most genets were confined to a single tree or stump (Table 1). A total of 32 genets was found to have spread secondarily to more than one tree or stump. Although this number represents only $14 \%$ of all genets, the basal area occupied by these "multitree" genets (we use this expression even if genets include stumps, because in the majority of cases the stumps were infected as trees before felling) averaged 33\% per site (range 13 to 56\%). Direct tree-to-tree spread was a likely mode of expansion of the multitree genets. In $23(72 \%)$ multitree genets, identical genotypes were obtained from adjacent roots of different trees. In the remaining cases, identical fungal genotypes were retrieved from points that, although next to each other, were not immediately contiguous (e.g., boles of adjacent trees or roots of neighboring trees growing in different directions). Missing points in the sampling scheme, failed isolations, or lack of viable mycelium in roots long colonized by $H$. annosum may account for this result.

There were considerable differences among sites regarding the incidence of multitree genets (Fig. 2). In two plots (Obsidian 1 and Owl), no multitree genets were found. Conversely, in Woodpile, Huey, and Mountain View, multitree genets represented 72, 62, and $57 \%$ of the basal area of each plot colonized by the pathogen (Table 1). Including all sites, individual multitree genets were found on two to seven stems per site (average $=3.6$ ). Stem density was significantly greater for sites with two or more multitree genets $(n=$

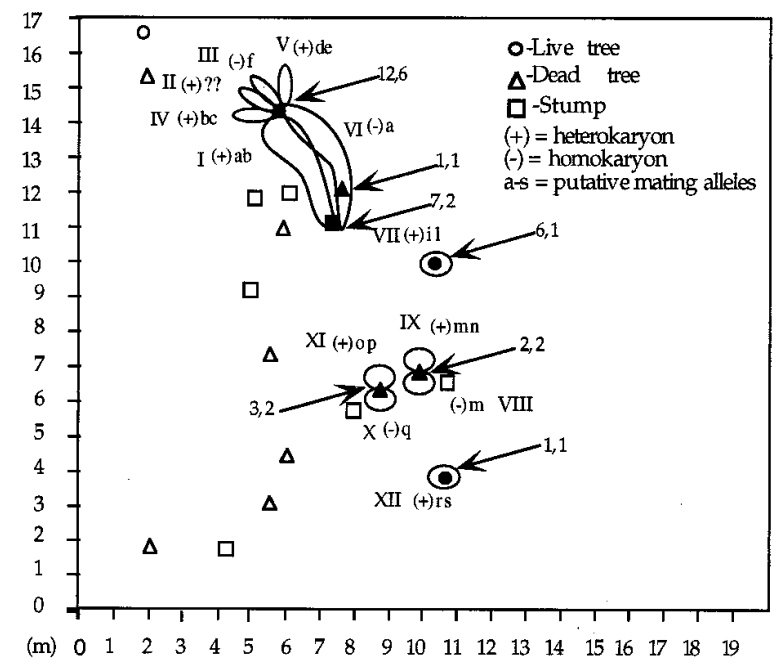

\section{Ridge 2}

Fig. 3. Distribution, size, and mating alleles of Heterobasidion annosum genets at Ridge 2 (Lassen National Forest). All trees and stumps in the area shown were sampled; shaded symbols indicate positive sample point. Arrows pointing at shaded symbols indicate the number of isolations and genets obtained from each tree or stump. Roman numerals indicate the different genotypes (Table 3), which are visualized by the solid lines encircling the trees from which they were isolated.
8 , average $=1,084$ stems per ha, $\mathrm{SD}=264$ ) than in sites with zero or one multitree genets $(n=7$, average $=739$ stems per ha, $\mathrm{SD}=$ 319) (Table 1) $(t=2.28, P=0.039)$.

Estimates of genet expansion were based on the distance between any two trees infected by a genet and the estimated time of onset of disease symptoms or death in the two trees in question. These estimates were obtained in seven mortality centers: 0.5 to $0.75 \mathrm{~m} /$ year in Ridge 2, $0.5 \mathrm{~m} /$ year in Mountain View, $1 \mathrm{~m} /$ year in Cougar, 0.25 to $0.7 \mathrm{~m} /$ year in Woodpile, $0.4 \mathrm{~m} /$ year in Meis Cabin, $0.7 \mathrm{~m} /$ year in Huey, and 0.5 to $0.9 \mathrm{~m} /$ year in Luey.

The maximum distance between the two furthest points in which the same genotype was collected ranged between 1.5 and $10 \mathrm{~m}$ (average $=5.5, \mathrm{SD}=2.4$ ). Distance values between two adjacent stems colonized by the same genet averaged $2.24 \mathrm{~m}(\mathrm{SD}=1.46$, range 1 to $5.9 \mathrm{~m}$ ). The distances between paired adjacent stems infected by the same genet and the diameters of the stems were highly correlated, suggesting that at our study sites the ability of the fungus to spread is linked to the size of the root system of the host and no free growth in soil is occurring. The largest $R^{2}$ values were obtained when regressing the maximum $\left(R^{2}=0.957\right)$ and the average $\left(R^{2}=0.922\right)$ distance between stem pairs against the sum of the two stem diameters (Fig. 1).

Stumps did not appear to be required for infection by $H$. annosum in white fir. A total of 196 genets were found in single stems, but only 12 genets $(6 \%)$ were from stumps infected after the tree had been felled. The remainder of the single-stem genotypes were found either in individual trees without any correlation to stump presence or in stumps that had been infected as living trees. Furthermore, our analysis of distribution of the disease and hosts suggested that, at least for 26 of 32 multitree genets (data not shown), either fungal genets were too far from stumps or the fungus was already established by the time the stumps were created in each site.

Mating alleles and AP-PCR fingerprinting of individual nuclei (parental homokaryons). In Cougar, 2 heterokaryotic and 11 homo-

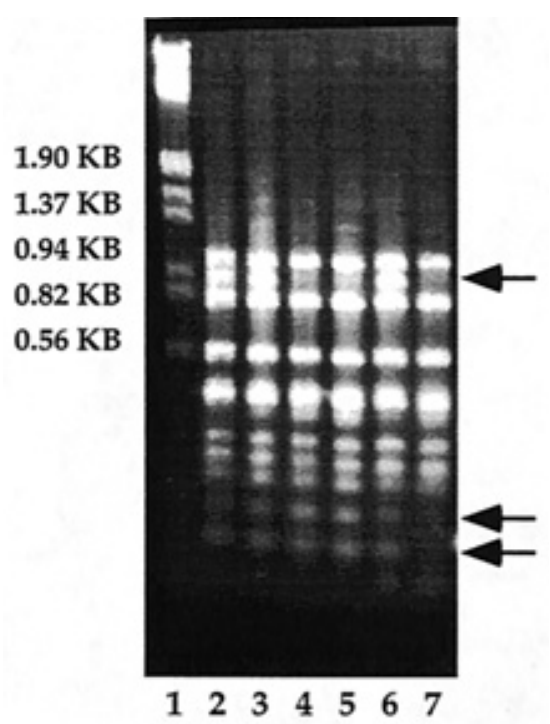

Fig. 4. A $1.5 \%$ agarose gel showing arbitrary-primed (AP)-polymerase chain reaction (PCR) results obtained with primers ITS1F-ctb6 on parental homokaryons of heterokaryotic genets I and IV in the Ridge 2 site. Amplicon patterns obtained for homokaryons bearing the same mating alleles were identical. In this case, three patterns (corresponding to three mating alleles) were obtained from four homokaryotic isolates, indicating that a parental homokaryon was shared by the two genets. Lane 1, Molecular standard Lambda cut by EcoRI and HindIII; lanes 2 and 3, parental homokaryon of genet IV bearing mating allele $\mathrm{b}$ (pattern 1); lanes 4 and 5, parental homokaryon of genet IV bearing mating allele c (pattern 2); lane 6, parental homokaryon of genet I bearing mating allele $\mathrm{b}$ (pattern 1); and lane 7, parental homokaryon of genet I bearing mating allele a (pattern 3). Arrows indicate polymorphic amplicons. Similar results were obtained with the other AP-PCR primers employed in this study. 
karyotic genets were isolated (Table 3 ). H. annosum is a basidiomycete with a bipolar mating system $(12,31)$; thus, a maximum of 15 mating alleles are possible for the Cougar site. Two alleles from heterokaryon III and one from homokaryon IX were not determined. A total of 10 mating alleles were identified. One heterokaryotic and one homokaryotic genets shared an identical mating allele and were collected each from the same two adjacent trees.

In Ridge 2, eight heterokaryotic and four homokaryotic genets were isolated (Table 3, Fig. 3); thus, a maximum of 20 alleles could be found at that site. Two alleles from heterokaryon II were not determined, and a total of 15 mating alleles were identified. Identical mating alleles were shared by heterokaryotic genets I and IV (allele b), by heterokaryon I and homokaryon VI (allele a), and by heterokaryon IX and homokaryon VIII (allele m). In all cases, genets that shared mating alleles were spatially adjacent to each other.

Genotypes that shared a mating allele were found to share a common nucleus. This is demonstrated by AP-PCR fingerprints of homokaryotic isolates (Fig. 4). Homokaryon VIII and heterokaryon IX were also both characterized by the presence of an intron in the mitochondrial LrRNA gene. This intron is rarely found in S ISG populations and its presence was determined by the size ( 2 kilobases $[\mathrm{kb}]$ ) of the amplicon obtained by using the ML5-ML6 primer pair. All other isolates in Ridge 2 and Cougar yielded the expected $1.85-\mathrm{kb}$ amplicon. Because the size of the exonic portion of the gene is approximately 400 base pairs (bp), the remaining has to be accounted for by introns of different sizes in the two ISGs (approximately $1,450 \mathrm{bp}$ in $\mathrm{S}$ isolates and approximately $1,600 \mathrm{bp}$ in $\mathrm{P}$ isolates) (20).

\section{DISCUSSION}

Patterns of fungal distribution: Host specificity, within-tree localization, and inferred modes of initial disease development. $H$. annosum isolates were obtained mostly from the sapwood and roots of white fir trees and stumps. The frequent occurrence of $H$. annosum in the sapwood rather than in the heartwood and the symptoms observed in the host trees show that this fungus is a serious pathogen of white fir in California. The effects of $H$. annosum on white fir may vary depending on the amount of sapwood in the tree, the defense mechanisms triggered in the host, and the general ecological and climatic conditions at the site (17,36). All isolates belonged to the S ISG and, with two exceptions (one ponderosa pine and one incense cedar), the only species affected by $H$. annosum was white fir. $H$. annosum ISG S thus displayed a high level of host specificity in ecologically mesic, mixed-conifer stands with a predominance of white fir.

The isolation of $H$. annosum from the sound inner sapwood of asymptomatic trees, combined with the presence of a completely healthy root system, may indicate that the fungus undergoes a latent phase between infection and pathogenic wood colonization. We speculate that the modified moisture/aeration regime in our cut wood samples may have triggered the extensive growth and sporulation of $H$. annosum and, in a parallel way, altered moisture/aeration regimes (e.g., because a wound or water stress may trigger the growth of the fungus in standing trees) (5). This has been well documented for other pathogenic fungi $(6,10,16,57)$, but further evidence is required to validate our observations for $H$. annosum in white fir.

Number of $\boldsymbol{H}$. annosum genotypes present in individual white fir mortality centers. Somatic compatibility tests and APPCR fingerprinting indicated that many different genotypes were present in each discrete mortality center. Both homokaryons and heterokaryons were collected. Genotypes defined by AP-PCR fingerprints perfectly matched our sc classifications in Cougar and Ridge 2. A good agreement of the two techniques is expected when sc systems are regulated by a large number of alleles at several loci, as shown for $H$. annosum (24), and when individuals are randomly mating (48). The distribution of many discrete genets ob- served in white fir mortality centers indicates that primary infections, presumably via basidiospores, are frequent.

Stumps are not essential primary infection centers. Primary infection appears not to be dependent on the presence of stumps. This conclusion was evident for the high proportion of small genets confined to single trees, particularly when the fungus was isolated only from the stem but not from the healthy-looking root system. In most multitree genets, it also appeared that the initial infection had not occurred on stump tops, either because the disease preceded stump creation or because the stumps were too far from the area occupied by the genet. Therefore, we conclude that live trees provide the most common infection courts for $H$. annosum in white fir stands of the Sierra Nevada and southern Cascades mountain ranges. Wounds may provide suitable infection courts for $H$. annosum on true firs (1), but further research is needed to address the issue.

The spatial distribution of fungal genets: Rates and modes of spread. Unlike Norway spruce, a species for which single genotypes per tree have been reported (53), several fungal genotypes were found in individual white fir trees. This may be explained by the fact that, as suggested above, true firs are amenable to infection both by aerial inoculum and by contact with fungus-colonized roots of adjacent trees or stumps. This combination of infection modes is similar to what is reported for H. annosum in Tsuga spp. (39), and it is in contrast with the known dynamics of establishment of H. annosum in Pinus and Picea spp., in which stump tops appear to be the predominant infection courts $(33,41,56)$.

Only $14 \%$ of the fungal genets had colonized more than one host tree. The low frequency of tree-to-tree spread suggests that expansion beyond the initial infection site may be a limited occurrence in the development of genets, similar to situations observed in four Armillaria spp. (60). Nevertheless, the role of these expanding genets in shaping mortality centers was significant, and on the average, they represented $33 \%$ of the colonized basal area. The area occupied by multitree genets was uninterrupted, except for some overlap with other genets colonizing the same trees. By taking into account stems from which positive isolations of $H$. annosum were obtained and trees or stumps that did not yield $H$. annosum isolates but displayed symptomatic wood decay, genet expansion could always be explained by direct tree-to-tree spread. No evident pattern of mitotic spore transmission was found within a mortality center (e.g., presence of spatially isolated ramets), but very short dispersal of conidia or mycelium (as airborne propagula or vectored by insects) could not be excluded. The longest distance covered by a single genet in any site was $10 \mathrm{~m}$ and the average was $5.5 \mathrm{~m}$. This is a much shorter distance compared with other root pathogens such as Armillaria spp. (47), but it is in agreement with values reported for $H$. annosum genets in Norway spruce in Europe $(53,56)$.

Estimates of fungal spread ranged from 0.2 to $1 \mathrm{~m} /$ year. These values match results obtained in a field inoculation study of white fir (21) and are comparable to values reported by others $(26,46)$. These estimates translate in a life span of 10 to 50 years for the largest $(10 \mathrm{~m})$ genet encountered. The estimated life span is much shorter than the age of the dominant and codominant trees (80 to 120 years) at any of our study sites. The data are best interpreted by excluding the possibility of carryover of fungal genets from oldgrowth white fir trees that had occupied the sites prior to the younger growth and by considering the existing genets as originated by primary infections on the current stand. Furthermore, if genets had expanded over long periods of time, the presence of ramets would be expected.

Tree-to-tree spread through root contacts or grafts appeared to be the most likely mode of contagion. Adjacent roots from different trees were colonized by the same genet in 23 of 32 multitree genets. The importance of such routes of contagion was also underlined by the fact that no free mycelium or evident root ectotrophic mycelium were encountered at our study sites.

Effects of clonal age, tree size, and stand density on evident patterns of secondary spread. In 12 of 15 study sites, multitree 
genets only colonized a few trees. This could be due either to the recent establishment of the pathogen in a site (this may be the case for Owl and Obsidian 1, where only a few isolates were obtained) or to the sites characteristics being unfavorable to the secondary spread of H. annosum (e.g., Dark Canyon and Loggers, where trees are well spaced). We hypothesize that with increasing clonal age and in the presence of conditions favorable to fungal spread, the number of larger genets per site may increase (Fig. 2). For instance, tree size and density appear to have an effect on the advance of other root pathogens such as Phellinus weirii in Douglas fir plantations (4). The regression analyses relating tree diameter with distance between trees colonized by the same genet showed that with increasing tree diameter the distance covered by a genet increased as well. This correlation also underlines the fact that $H$. annosum is highly dependent on the structure of the host (e.g., size of the root system) for its secondary spread and that no fungal growth is occurring in the soil via mycelial cords or rhizomorphs. This is in agreement with previous observations on this pathogen $(15,49,50)$.

High tree densities appear to favor secondary spread. In the three sites Woodpile, Mountain View, and Huey, secondarily expanding genets were prominent and individual genets encompassed up to 11 trees and expanded up to $10 \mathrm{~m}$. Tree densities in these areas were extremely high and were the likely cause for the successful expansion of $H$. annosum genets. Furthermore, there was a statistically significant higher tree density in sites with at least two multitree genets than in sites with zero or one multitree genets.

Genetic relatedness of fungal genotypes encountered in a site. The distribution and frequency of mating alleles and the molecular analysis provide further insights on the population dynamics of $H$. annosum in white fir. Since this fungus has a bipolar mating system, the same mating allele would be expected in $50 \%$ of the haploid meiotic progeny of any given individual or even in unrelated genotypes if that particular mating allele occurred in high frequency in the general population of the fungus. At both Cougar and Ridge 2, many different mating alleles were identified. This result is similar to results obtained by Chase and Ullrich (11) in a red pine plantation and is a clear indication that independent basidiospore infections have occurred in the two sites and that the source of the local inoculum is not a preestablished genet or a local prolific "fruiter," but rather a broader population. Broad breeding populations have also been reported for Armillaria spp. $(44,48)$.

Identical mating alleles and nuclei were shared in three cases by a homokaryotic and a heterokaryotic genet. Genotypes sharing nuclei were adjacent to each other, and in one case, the homokaryon and the heterokaryon (SIG VIII and IX in the Ridge 2 site) had an identically sized (approximately 1,600 bp) and a rare intron in the mitochondrial ribosomal region amplified by PCR with the ML5ML6 primer combination, indicating that the two genotypes may bear an identical mitochondrial genome. These results suggest that either these homokaryons were derived from the heterokaryon or that they represent portions of the thallus that were not heterokaryotized. The independence of homokaryotic components of heterokaryons has also been shown in the laboratory by Hansen et al. (23). By hyphal tipping, they showed that heterokaryons maintain parental homokaryotic hyphae intermingled with heterokaryotic hyphae in the thallus. Furthermore, field and greenhouse experiments $(13,19)$ have demonstrated that homokaryons can survive in nature and be virulent.

Two adjacent heterokaryons in Ridge 2 shared an identical nucleus. This situation could have arisen by di-mon mating or by heterokaryotization by different homokaryons of two separate sectors of the homokaryotic mycelium. Di-mon mating has long been known to be a frequent event in laboratory pairings of basidiomycetes $(7,8)$ and has been suggested in field studies based on distribution of mating alleles $(29,43)$ and restriction fragment length polymorphisms of diploid isolates (42), but this is the first report to provide direct evidence of the sharing of nuclei between spatially contiguous genets in nature.
Why are there discrete mortality centers? Although our research was not directed at assessing relative importance of different patterns of $H$. annosum infestations in white fir stands (i.e., clustered versus scattered), tree mortality in California is most frequently observed in root-disease centers comprised of several adjacent trees. We focused our study on the genetic structure of the pathogen within these clusters of mortality, but our results cannot fully explain why $H$. annosum mortality appears in such discrete infection centers. Whereas in some centers, an individual fungal genet does affect several contiguous trees; in most cases, secondary tree-to-tree spread is apparently strongly limited. We envision a possible mechanism for center formation consistent with our results. Environmental conditions and physiological status (e.g., increased transpiration rates that modify the oxygen/water ratio in the wood) may be affected in trees surrounding dead trees, making them more suitable for colonization by $H$. annosum and other pests or pathogens. This could also be true for trees around newly created stumps. Furthermore, H. annosum may be already present, but inactive, in a large number of host trees. A new physiological or environmental condition may trigger the pathogenic activity of the fungus in a tree, leading to the colonization of the lower portion of the bole and the roots. Roots of neighboring trees in contact with roots of the "symptomatic" tree become physiologically dysfunctional through colonization by the expanding fungal genet, leading to activation of resident genotypes of the pathogen maybe via water stress. The newly activated genotypes will start expanding and consequently will both activate more genotypes and competitively block the expansion of the previously activated genotypes. The final outcome would be that of a group of adjacent symptomatic or dead trees colonized by different genotypes.

\section{ACKNOWLEDGMENTS}

This study was funded, in part, by the USDA Competitive Grant \#9337101-8701. We thank the many working crews from the California Conservation Camps, the California Department of Forestry, and the Fire Crews of the USDA Forest Service for assistance in the field sampling work.

\section{LITERATURE CITED}

1. Aho, P. E., Fiddler, G., and Srago, M. 1983. Logging damage in thinned second-growth true fir stands in California and recommendations for control. Pac. Northwest For. Range Exp. Stn. For. Serv. U.S. Dep. Agric. PNW-304.

2. Anderson, J. B., and Kohn, L. M. 1995. Clonality in soilborne, plantpathogenic fungi. Annu. Rev. Phytopathol. 33:369-391.

3. Bae, H., Hansen, E. M., and Strauss, S. H. 1994. Restriction fragment length polymorphisms demonstrate single origin of infection centers in Phellinus weirii. Can. J. Bot. 72:440-447

4. Bloomberg, W. J., and Reynolds, G. 1982. Factors affecting transfer and spread of Phellinus weirii mycelium in roots of second-growth Douglasfir. Can. J. For. Res. 12:424-427.

5. Boddy, L., and Rayner, A. D. M. 1983. Origins of decay in living deciduous trees: The role of moisture content and re-appraisal of the expanded concept of tree decay. New Phytol. 94:623-641.

6. Boddy, L., and Rayner, A. D. M. 1984. Fungi inhabiting oak twigs before and at fall. Trans. Br. Mycol. Soc. 82:501-505.

7. Buller, A. H. R. 1930. The biological significance of conjugate nuclei in Coprinus lagopus and other Hymenomycetes. Nature 126:686-689.

8. Buller, A. H. R. 1931. Researches on Fungi. Hafner Publishing Co., New York.

9. Capretti, P., Korhonen, K., Mugnai, L., and Romagnoli, C. 1990. An intersterility group of Heterobasidion annosum specialized to Abies alba. Eur. J. For. Pathol. 20:231-240.

10. Chapela, I., and Boddy, L. 1988. Fungal colonization of attached beech branches. I. Early stages of development of fungal communities. New Phytol. 110:39-46.

11. Chase, T. E., and Ullrich, R. C. 1983. Sexuality, distribution, and dispersal of Heterobasidion annosum in pine plantations of Vermont. Mycologia 75:825-831.

12. Chase, T. E., and Ullrich, R. C. 1990. Genetic basis of biological species in Heterobasidion annosum: Mendelian determinants. Mycologia 82:67-72.

13. Cobb, Jr., F., Chase, T., Otrosina, W., Ratcliff, A., and Popenuck, T. 
1989. Comparative virulence of Heterobasidion annosum isolates. Phytopathology 79:1164.

14. Cubeta, M. A., Briones-Ortega, R., and Vilgalys, R. 1993. Reassessment of heterokaryon formation in Rhizoctonia solani anastomosis group 4. Mycologia 85:777-787.

15. Curl, E. A., and Arnold, M. M. 1964. Influence of substrate and microbial interactions on growth of Fomes annosus. Phytopathology 54:1486-1487.

16. Etheridge, D. E., and Craig, H. M. 1976. Factors influencing infection and initiation of decay by the Indian paint fungus (Echinodontium tinctorium) in western hemlock. Can. J. For. Res. 6:299-318.

17. Garbelotto, M. 1996. The genetic structure of populations of Heterobasidion annosum (Fr.) Bref. from the global to the local scale: Implications for the biology, the epidemiology, and the evolution of a forest pathogen. Ph.D. dissertation. University of California, Berkeley.

18. Garbelotto, M., Bruns, T. D., Cobb, Jr., F. W., and Otrosina, W. J. 1993. Differentiation of intersterility groups and geographic provenances among isolates of Heterobasidion annosum detected by random amplified polymorphic DNA assays. Can. J. Bot. 71:565-569.

19. Garbelotto, M., Lee, K. K., Slaughter, G., Popenuck, T., Cobb, F. W., and Bruns, T. D. 1997. Heterokaryosis is not required for virulence of Heterobasidion annosum. Mycologia 89:92-102.

20. Garbelotto, M., Ratcliff, A., Bruns, T. D., Cobb, F. W., and Otrosina, W. J. 1996. Use of taxon-specific competitive-priming PCR to study host specificity, hybridization, and intergroup gene flow in intersterility groups of Heterobasidion annosum. Phytopathology 86:543-551.

21. Garbelotto, M., Slaughter, G., Popenuck, T., Cobb, F. W., and Bruns, T. D. 1997. Secondary spread of Heterobasidion annosum in white fir rootdisease centers. Can. J. For. Res. 27:766-773.

22. Gardes, M., and Bruns, T. D. 1993. ITS primers with enhanced specificity for fungi and Basidiomycetes: Application to the identification of mycorrhizae and rusts. Mol. Ecol. 2:113-118.

23. Hansen, E. M., Stenlid, J., and Johansson, M. 1993. Somatic incompatibility and nuclear reassortment in Heterobasidion annosum. Mycol. Res. 97:1223-1228.

24. Hansen, E. M., Stenlid, J., and Johansson, M. 1993. Genetic control of somatic incompatibility in the root-rotting basidiomycete Heterobasidion annosum. Mycol. Res. 97:1229-1233.

25. Harrington, T. C., Rizzo, D. M., Descenzo, R. A., and Steimel, J. 1998. Genetic relationships among clones of Heterobasidion annosum in a pine forest. Pages 159-170 in: Root and Butt Rots of Forest Trees, Les Colloques No. 89. C. Dealtour, J. J. Guillaumin, B. Lung-Escarmant, and B. Marçais, eds. INRA, Paris, France.

26. Hodges, C. S. 1969. Modes of infection and spread of Fomes annosus. Annu. Rev. Phytopathol. 7:247-266.

27. Hunt, R. S., and Cobb, Jr., F. W. 1971. Selective medium for the isolation of wood-rotting basidiomycetes. Can. J. Bot. 49:2064-2065.

28. Hunt, R. S., Cobb, Jr., F. W., and Parmeter, Jr., J. R. 1976. Fomes annosus stump colonization and fungus development in the California mixedconifer type. Can. J. For. Res. 6:159-165.

29. Kay, E., and Vilgalys, R. 1992. Spatial distribution and genetic relationships among individuals in a natural population of the oyster mushroom Pleurotus ostreatus. Mycologia 84:173-182.

30. Kim, W. K., Zerucha, T., and Klassen, G. R. 1992. A region of heterogeneity adjacent to the $5 \mathrm{~S}$ ribosomal RNA gene of cereal rusts. Curr. Genet. 22:101-105.

31. Korhonen, K. 1978. Intersterility groups of Heterobasidion annosum. Commun. Inst. For. Fenn. 94:1-25.

32. Li, Y. 1995. Molecular characterization and evolution of mitochondrial introns within the large subunit ribosomal RNA genes of Suillus. Ph.D. dissertation. University of California, Berkeley.

33. Morrison, D. J., and Johnson, L. S. 1978. Stump colonization and spread of Fomes annosus 5 years after thinning. Can. J. For. Res. 8:177-180.

34. Morrison, D. J., Larock, M. D., and Waters, A. J. 1986. Stump infection by Fomes annosus in spaced stands in the Prince Rupert Forest Region of British Columbia. Can. For. Serv. Pac. For. Cent. Inf. BC-X-285.

35. Otrosina, W. J., Chase, T. E., Cobb, Jr., F. W., and Korhonen, K. 1993. Population structure of Heterobasidion annosum from North America and Europe. Can. J. Bot. 71:1064-1071.

36. Otrosina, W. J., and Cobb, Jr., F. W. 1989. Biology, ecology and epidemiology of Heterobasidion annosum. Pages 26-33 in: Proc. Symp. Res. Manag. Annosus Root Dis. (Heterobasidion annosum) Western North Am. W. J. Otrosina and R. F. Scharpf, eds. U.S. Dep. Agric. For. Serv., Monterey, CA.

37. Rayner, A. D. M. 1991. The phytopathological significance of mycelial individualism. Annu. Rev. Phytopathol. 29:305-323.

38. Rayner, A. D. M., and Todd, N. K. 1977. Intraspecific antagonism in natural populations of wood-decaying Basidiomycetes. J. Gen. Microbiol. 103:85-90.

39. Rhoads, A. S., and Wright, E. 1946. Fomes annosus commonly a wound pathogen rather than a root parasite of western hemlock in western Oregon and Washington. J. For. 44:1091-1092.

40. Rishbeth, J. 1950. Observations on the biology of Fomes annosus, with particular reference to East Anglian pine plantations. I. The outbreaks of disease and ecological status of the fungus. Ann. Bot. 14:265-283.

41. Rishbeth, J. 1951. Observations on the biology of Fomes annosus, with particular reference to East Anglian pine plantations. III. Natural and experimental infection of pines, and some factors affecting severity of the disease. Ann. Bot. 15:221-247.

42. Rizzo, D. M., Blanchette, R. A., and May, G. 1995. Distribution of $A r-$ millaria ostoyae genets in a Pinus resinosa-Pinus banksiana forest. Can. J. Bot. 73:776-787.

43. Rizzo, D. M., Smereka, K. J., and Harrington, T. C. 1990. Notes on the rhizomorphs and mating systems of Xeromphalina campanella. Mycologia 82(5):651-655.

44. Saville, B. J., Yoell, H., and Anderson, J. B. 1996. Genetic exchange and recombination in populations of the root-infecting fungus Armillaria gallica. Mol. Ecol. 5:485-497.

45. Sinclair, W. A. 1964. Root- and butt-rot of conifers caused by Fomes annosus with the special reference to inoculum dispersal and control of the disease in New York. Mem. Cornell Univ. Agric. Exp. Stn. 391:54.

46. Slaughter, G. W., and Parmeter, Jr., J. R. 1995. Enlargement of treemortality centers surrounding pine stumps infected by Heterobasidion annosum in northeastern California. Can. J. For. Res. 25:244-252.

47. Smith, M. L., Bruhn, J. N., and Anderson, J. B. 1992. The fungus Armillaria bulbosa is among the largest and the oldest living organisms. Nature 356:428-431.

48. Smith, M. L., Bruhn, J. N., and Anderson, J. B. 1994. Relatedness and spatial distribution of Armillaria genets infecting red pine seedlings. Phytopathology 84:822-829.

49. Srago, M. D. 1973. The influence of soil biological and physical factors on the growth of Fomes annosus. Ph.D. dissertation. University of California, Berkeley.

50. Srago, M., and Cobb, F. W. 1974. Influence of soil biological factors on the mycelial growth of Fomes annosus. Pages 218-226 in: Proc. Int. Conf. Fomes Annosus, 4th. E. G. Kuhlman, ed. USDA Forest Service, Athens, GA.

51. Srago, M., Parmeter, J. R. J., Johnson, J., and West, L. 1978. Determining Early Failure of Root Diseased Incense-Cedars in Yosemite Valley. U.S. Dep. Agric. For. Serv., and U.S. Dep. Interior, Natl. Park Serv.

52. Stambaugh, W. J. 1989. Annosus root disease in Europe and the southeastern United States: Occurrence, research, and historical perspective. Pages 3-9 in: Proc. Symp. Res. Manag. Annosus Root Dis. (Heterobasidion annosum) in Western North Am. W. J. Otrosina and R. F. Scharpf, eds. U.S. Dep. Agric., For. Serv., Monterey, CA.

53. Stenlid, J. 1985. Population structure of Heterobasidion annosum as determined by somatic incompatibility, sexual incompatibility, and isoenzyme patterns. Can. J. Bot. 63:2268-2273.

54. Stenlid, J., and Karlsson, J. 1991. Partial intersterility in Heterobasidion annosum. Mycologia 95:1153-1159.

55. Stenlid, J., Karlsson, J., and Högberg, N. 1994. Intraspecific genetic variation in Heterobasidion annosum revealed by amplification of minisatellite DNA. Mycol. Res. 98:57-63.

56. Swedjemark, G., and Stenlid, J. 1993. Population dynamics of the root rot fungus Heterobasidion annosum following thinning of Picea abies. Oikos 66:247-254.

57. Webber, J. F., and Gibbs, J. N. 1984. Colonization of elm bark by Phomopsis oblonga. Trans. Br. Mycol. Soc. 82:352-354.

58. Welsh, J., and McClelland, M. 1990. Fingerprinting genomes using PCR with arbitrary primers. Nucleic Acids Res. 18:7213-7218.

59. White, T. J., Bruns, T. D., Lee, S., and Taylor, J. 1990. Amplification and direct sequencing of fungal ribosomal RNA genes for phylogenetics. Pages 315-322 in: PCR Protocols: A Guide to Methods and Applications. M. A. Innis, D. H. Gelfand, J. J. Sninsky, and T. J. White, eds. Academic Press, New York.

60. Worrall, J. J. 1994. Population structure of Armillaria species in several forest types. Mycologia 86:401-407.

61. Worrall, J. J., Parmeter, Jr., J. R., and Cobb, Jr., F. W. 1983. Host specialization of Heterobasidion annosum. Phytopathology 73:304-307. 